\title{
QUALITATIVE AND QUANTITATIVE METHODS OF STUDYING THE EFFECT OF LIPIDS ON BACTERIA GROWN ON THE SURFACE OF SOLID CULTURE MEDIA
}

\author{
C. Davidson*, Cerilan Rogers*, Anne E. Taylor*, D.F.J. Brown† and G.R.E. Naylor \\ Department of Pathology, University of Cambridge, Tennis Court Road, Cambridge CB2 IQP, \\ and + Public Health Laboratory, Addenbrooke's Hospital, Cambridge CB2 $2 Q U$
}

VARIOUS views are held about the antibacterial mechanisms operating on the skin surface (for reviews see Burtenshaw, 1945; Naylor and Rook, 1968). Substances resembling long-chain fatty acids extracted from normal skin by Burtenshaw (1945) had a marked bactericidal action on Streptococcus pyogenes. Ricketts, Squire and Topley (1951) suggested that a chemical mechanism was largely responsible for the destruction of Str. pyogenes on the skin, whereas drying is responsible for the destruction of Escherichia coli and Pseudomonas aeruginosa; both factors appeared to contribute to the elimination of Staphylococcus aureus. They concluded that unsaturated fatty acids, particularly oleic acid, are the active chemical agents. These fatty acids may be produced on the skin surface as a result of the splitting of esters in the sebum by the commensal flora (Scheimann et al., 1960; Davidson, 1965; Naylor, 1970).

Many workers have studied the antibacterial action of lipids in vitro (Walker, 1924; Dubos, 1947; Pollock, 1948; Nieman, 1954; Galbraith et al., 1971; Butcher, King and Dyke, 1976), usually in fluid media in which suspensions of bacteria had been added to emulsions of various lipids. Burtenshaw (1945) was unable to demonstrate an antibacterial effect with lipid substances placed in punched-out holes in an agar medium containing haemolytic streptococci; he concluded that antibacterial lipids did not diffuse in agar medium. Dubos (1947) described the influence of various lipids incorporated in solid media on the number and diameter of bacterial colonies.

Because the lipids on the skin probably exist as a water-in-lipid emulsion (Herrmann, Prose and Sulzberger, 1953), experimental procedures with a solid medium probably imitate the physical conditions on the skin better than studies of suspensions of bacteria in aqueous solutions containing fine droplets of emulsified lipid (Milyani and Selwyn, 1978). The following qualitative and quantitative studies take account of this view. A preliminary report of the qualitative method was given by Naylor (1970).

\section{MATERIALS AND METHODS}

Bacterial strains. Str. pyogenes group A, type Imp 19, strain 28441 was isolated during an impetigo epidemic and was obtained from the late Dr R. M. Fry. Str. pyogenes group A, type M12, strain 83470 was isolated from a patient with a sore throat and was obtained from Dr J. M. Boissard. Two strains of Corynebacterium parvum (Propionibacterium acnes) (CN5936 and CN6276) were obtained from Professor R. Carne. Strains of Staph. aureus, Staph. epidermidis, $P$ s. aeruginosa and E. coli were obtained from the Department of Pathology, University of Cambridge.

Qualitative tests of lipid activity. The C.parvum strains were grown on Brain-Heart Infusion Agar (Oxoid Ltd, Wade Road, Basingstoke, Hampshire). Streptococci and staphylococci were grown on Hartley's digest agar (Hartley's Digest Broth, code PM1185 solidified with 1\%

Received 3 Sept. 1979; revised version accepted 26 Nov. 1979.

* Medical students reading pathology in Part II of the Natural Sciences Tripos, University of Cambridge. Requests for reprints should be addressed to Dr G. R. E. Naylor, Department of Pathology, University of Cambridge, Tennis Court Road, Cambridge CB2 1QP. 
Bacteriological Agar, code L11, Oxoid Ltd), with $5 \mathrm{ml}$ of $20 \%$ (w/v) Seitz-filtered Peptone (Evans Medical Ltd, Speke, Liverpool) added per $100 \mathrm{ml}$ of agar. All media contained $0.01 \%(\mathrm{w} / \mathrm{v})$ triphenyl tetrazolium chloride (Hopkin and Williams, PO Box 1, Romford, Essex).

Agar plates were inoculated by spreading, with a wire loop, a lawn of inoculum from two large loopfuls of an overnight broth culture of the organism. The lipids were placed on 9-cm diameter sterile filter paper disks (Whatman Qualitative I); drops (10-15 mg) of each lipid under test, undiluted or diluted in light liquid paraffin (Hopkin and Williams), were placed around the periphery of the filter paper disk. As a control, liquid paraffin alone was used. The filter paper was then placed on the inoculated plate, care being taken to avoid trapping air bubbles. Plates were incubated overnight at $37^{\circ} \mathrm{C}$ in duplicate under aerobic and anaerobic conditions. A Gaspak (Baltimore Biological Laboratories, York House, Empire Way, Wembley, Middlesex) was used to produce the anaerobic conditions in an anaerobic jar.

The degree of bacterial growth under the lipid droplets was judged as complete inhibition (no red formazan produced), gross inhibition, slight inhibition, growth as control area of the plate with liquid paraffin alone, and enhanced growth; these judgements were based on the degree of coloration caused by the production of formazan. Oleic acid $(92 \%)$ was obtained from B.D.H. Chemicals Ltd, Fourways, Atherstone, Warwickshire, and cis-linoleic acid (90-95\%, Grade II) from Sigma Chemical Co. Ltd, Fancy Road, Poole, Dorset.

Quantitative tests of lipid activity. The streptococci were grown on layered blood-agar plates containing 5-7\% defibrinated horse-blood (Department of Clinical Veterinary Medicine, University of Cambridge). All other strains were grown on nutrient-agar plates.

Pieces of sterile filter paper (Whatman Qualitative 1) $2 \mathrm{~cm}$ square were saturated with $40 \mu$ lof lipid diluted in ethanol. The paper squares were dried by circulating air in an oven at $40^{\circ} \mathrm{C}$ for 30 min. to evaporate the ethanol. Agar plates were seeded by flooding with an overnight digestbroth culture of the test organism; after removal of excess broth with a pasteur pipette, the plates were dried at $37^{\circ} \mathrm{C}$ for $30 \mathrm{~min}$. with the lids raised; this gave an even lawn of growth on each plate. The papers impregnated with different amounts of fatty acid were arranged on the inoculated plates which were incubated at $37^{\circ} \mathrm{C}$. Each plate included a control paper which had had $40 \mu \mathrm{l}$ of ethanol added to it and had then been dried. Overnight incubation was aerobic or anaerobic (Gaspak, B.B.L.).

After incubation of plates, the papers were removed with forceps; circular plugs of agar, $1 \mathrm{~cm}$ in diameter, were cut from the agar under the papers with separate sterile cork borers. The plugs of agar were transferred by a sterile hypodermic needle to "stomacher" bags to which $5 \mathrm{ml}$ of sterile Phosphate Buffered Saline (Oxoid Ltd, code BR 14a) were added. They were then macerated for approximately $20 \mathrm{~s}$ in a Colworth 80 stomacher (Sharpe and Jackson, 1972). Viable counts were then performed on the resulting suspensions by the droplette method on $0 \cdot 8 \%$ tryptic soy agar (Sharpe et al., 1972).

\section{RESULTS}

\section{Qualitative Studies}

The effects of oleic and linoleic acids, diluted in liquid paraffin, on the anaerobic growth of a range of bacteria on the surface of agar media are summarised in the table. Virtually identical results were obtained in parallel aerobic tests with all of these organisms, except C.parvum which could not be tested aerobically.

Oleic acid inhibited the growth of Staph. aureus and Staph. epidermidis, but only when undiluted, whereas it produced a gradient of inhibition decreasing with dilution in tests with Str. pyogenes type Imp 19. Linoleic acid was a more potent inhibitor of all three test organisms, Str. pyogenes type Imp 19 being most susceptible and Staph. epidermidis least susceptible. Both acids apparently had a stimulatory effect on the growth of $C$. parvum, although the effect of linoleic acid was slightly less than that of oleic acid.

\section{Quantitative Studies}

The inhibitory effects of oleic and linoleic acids on various organisms are shown in the figure. 


\section{Table I}

Effect of oleic and linoleic acids on the growth of bacteria on the surface of an agar medium, determined by a qualitative technique

\begin{tabular}{|c|c|c|c|c|c|c|c|}
\hline \multirow{2}{*}{ Organism } & \multirow[b]{2}{*}{$\begin{array}{l}\text { Fatty } \\
\text { acid }\end{array}$} & \multicolumn{6}{|c|}{ Degree of growth* in presence of the fatty acid diluted 1 in } \\
\hline & & $\begin{array}{c}1 \\
\text { (undiluted) }\end{array}$ & 10 & 20 & 40 & 80 & 160 \\
\hline Streptococcus pyogenes, type Imp 19 & $\left\{\begin{array}{l}\text { oleic } \\
\text { linoleic }\end{array}\right.$ & - & \pm & $\begin{array}{l}+ \\
-\end{array}$ & ++ & $\begin{array}{c}++ \\
-\end{array}$ & $\begin{array}{c}++ \\
-\end{array}$ \\
\hline Staphylococcus aureus & $\left\{\begin{array}{l}\text { oleic } \\
\text { linoleic }\end{array}\right.$ & \pm & $\begin{array}{c}+ \\
-\end{array}$ & $\begin{array}{c}+ \\
-\end{array}$ & $\begin{array}{c}++ \\
\pm\end{array}$ & $\begin{array}{c}++ \\
+\end{array}$ & $\begin{array}{l}+t \\
++\end{array}$ \\
\hline Staph. epidermidis & $\left\{\begin{array}{l}\text { oleic } \\
\text { linoleic }\end{array}\right.$ & $\begin{array}{l} \pm \\
\pm\end{array}$ & $\begin{array}{c}++ \\
\pm\end{array}$ & $\begin{array}{c}++ \\
\pm\end{array}$ & $\begin{array}{c}++ \\
+\end{array}$ & $\begin{array}{l}++ \\
++\end{array}$ & $\begin{array}{l}++ \\
++\end{array}$ \\
\hline Corynebacterium parvum (2 strains) & $\left\{\begin{array}{l}\text { oleic } \\
\text { linoleic }\end{array}\right.$ & $\begin{array}{c}++ \\
++\end{array}$ & $\begin{array}{l}+++ \\
+++\end{array}$ & $\begin{array}{l}+++ \\
+++\end{array}$ & $\begin{array}{l}+++ \\
+++\end{array}$ & $\begin{array}{l}+++ \\
+++\end{array}$ & $\begin{array}{l}+++ \\
+++\end{array}$ \\
\hline
\end{tabular}

* Judged by the degree of red coloration produced by reduction of colourless triphenyltetrazolium chloride in the medium to red triphenylformazan. Incubation was anaerobic. - = Complete inhibition, $\pm=$ gross inhibition, $+=$ slight inhibition, $++=$ growth as control (liquid paraffin alone), $++=$ enhanced growth.

Each graph plots the mean results of two experiments, some of which were repeated after an interval of 12 months without inconsistency.

With each organism-lipid combination the inhibition was more pronounced on the aerobically incubated plates. Linoleic acid was the more potent inhibitor of bacterial growth for all organisms investigated except the gram-negative bacilli (figure, $e$ and $f$ ).

Oleic acid was more inhibitory for Str.pyogenes type M12 strain 83470 (figure, a) than for Str. pyogenes type Imp 19 (figure, b) in aerobic and in anaerobic tests. This was true in anaerobic tests with linoleic acid; but under aerobic conditions, linoleic acid was markedly inhibitory for both of these streptococci.

Oleic acid did not significantly influence the growth of Staph. epidermidis (figure, c) or Staph. aureus (figure, d), but linoleic acid was markedly inhibitory, with a gradient of inhibition decreasing with dilution. This was most evident under aerobic conditions, when linoleic acid was marginally more potent against Staph. aureus than against Staph.epidermidis; this order was reversed in the anaerobic tests.

Neither fatty acid inhibited the growth of $E$. coli under aerobic or anaerobic conditions (figure, e) or Ps. aeruginosa (aerobic conditions only; figure, f).

\section{DisCuSSION}

We have described qualitative and quantitative methods of investigating the antibacterial activity of lipids on solid media.

The fatty acids on the skin surface are derived from triglycerides secreted in the sebum, which are without antibacterial effect (Davidson, 1965); the triglycerides are converted to inhibitory free fatty acids largely by lipases derived from the normal flora of the skin surface. The location of these lipases has been thoroughly investigated. The three main components of the resident flora of the skin, coagulase-negative, non-pigmented gram-positive cocci (staphylococci and micrococci), anaerobic diphtheroids, e.g., C.acnes (now designated Propio. acnes) and the yeast Pityrosporum (Somerville, 1969), have all been shown to have the potential to hydrolyse 

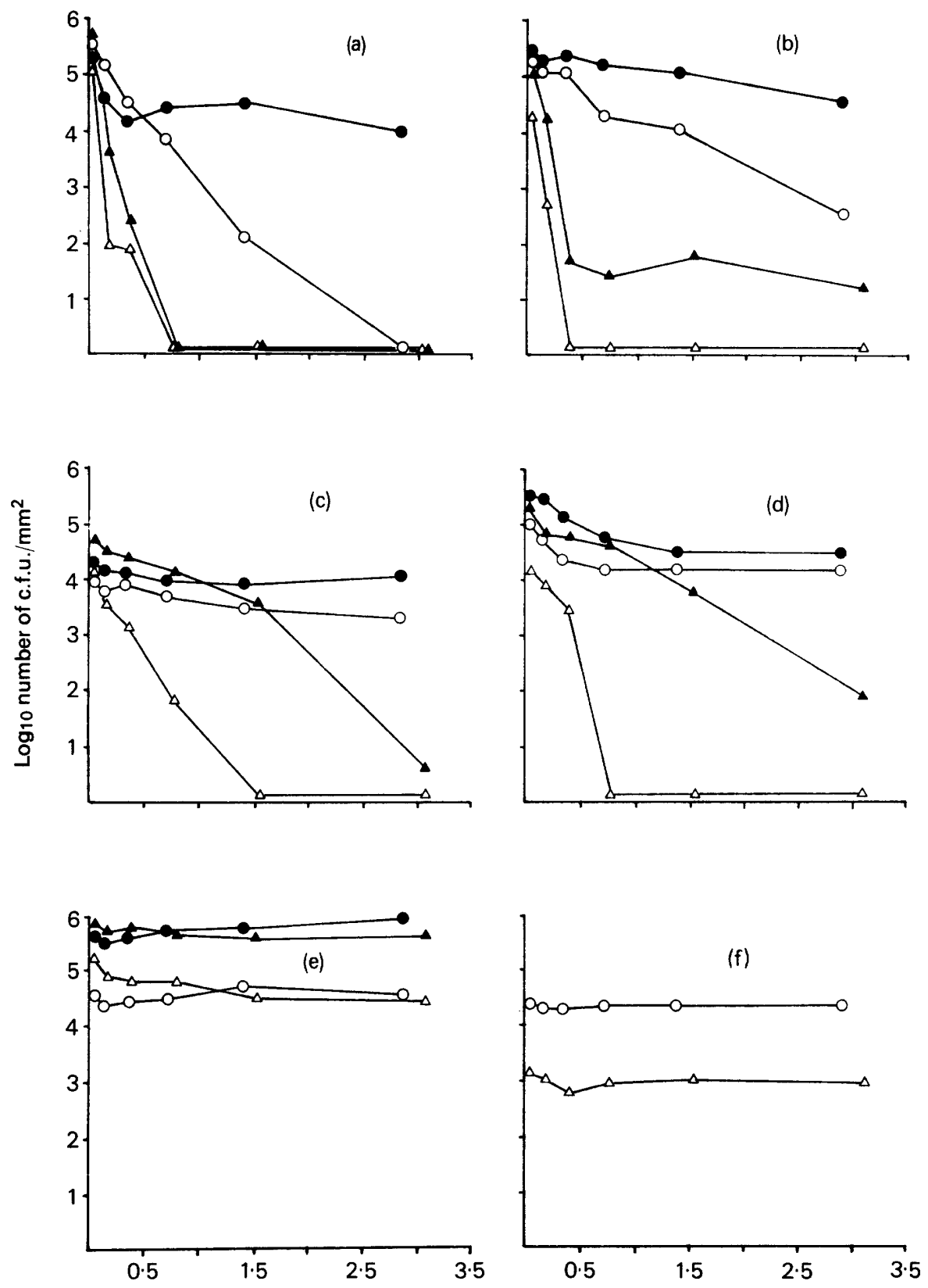

Fatty acid concentration $\left(\mu \mathrm{mol} / \mathrm{mm}^{2}\right)$

FIG.-Effect of oleic acid ( -- aerobic and -- anaerobic incubation) and linoleic acid ( $-\Delta-$ aerobic and - anaerobic incubation) on the growth of (a) Streptococcus pyogenes strain 83470, (b) Str. pyogenes type Imp 19, (c) Staphylococcus epidermidis, (d) Staph. aureus, (e) Escherichia coli, and (f) Pseudomonas aeruginosa (aerobic only), determined by a quantitative technique. 
triglycerides to liberate free fatty acids (Freinkel, 1968; Reisner et al., 1968; Reisner and Puhvel, 1969; Marples et al., 1970; Holt, 1971; Marples, Downing and Kligman, 1972; Butcher et al., 1976). Work on the optimal $p \mathrm{H}$ of bacterial lipases (Freinkel and Shen, 1969) and on the selective inhibition of components of the normal flora by various chemotherapeutic agents (Marples et al., 1970; Marples, Downing and Kligman, 1971; Marples et al., 1972) suggests that C. acnes plays a dominant role in the lipolysis of sebum. Micrococci are capable of maintaining a high proportion of acids on the surface if the population of C. acnes is suppressed (Marples $e t$ al., 1971).

In some of the earliest in-vitro work on these bacterial lipases, Davidson (1965) worked with micrococci and showed that the lipolytic activity persisted even after death of the microorganisms. The in-vivo studies of Scheimann et al. (1960) with neomycin and other antibiotics on the skin showed that inhibition of the normal flora interfered with free fatty-acid production.

In the present work, the antibacterial action of lipids has been studied by sowing a lawn of the test bacteria on a suitable solid medium and then covering the solid medium with filter paper impregnated with lipid. In this way the organisms were sandwiched between a nutrient aqueous phase in the culture medium and a lipid phase in the filter paper. The amount of lipid applied to the filter paper has been varied either by dilution with an inert lipid, liquid paraffin, or by diluting the lipid in ethanol and evaporating the ethanol before placing the filter paper on the lawn of bacteria. In qualitative studies bacterial growth was made visible by incorporating in the medium triphenyl tetrazolium chloride, which is reduced during bacterial growth to the red insoluble pigment triphenyl formazan. Quantitative studies were done by counting the numbers of viable organisms in the suspension resulting from maceration of a plug of agar medium taken from under the filter paper. Cultures were incubated aerobically and anaerobically in parallel.

The results obtained in our studies of skin lipids confirm and extend the observations of others (Burtenshaw, 1945; Dubos, 1947; Ricketts et al., 1951; Puhvel and Reisner, 1970; Aly et al., 1972). Unsaturated fatty acids, oleic and linoleic acids, inhibit Str. pyogenes markedly, Staph. aureus and Staph. epidermidis to a lesser extent, and have no inhibitory effect on gram-negative bacilli, E. coli and Ps. aeruginosa, the death of which on the skin is caused by drying (Ricketts et al., 1951; McBride, Duncan and Knox, 1975). The reason for the greater activity of the fatty acids in aerobic than in anaerobic atmospheres is unclear and the situation is complicated by the carbon dioxide generated by the Gaspaks which were used to produce anaerobic conditions.

Kodicek and Worden (1945) suggested that growth inhibition of bacteria by fatty acids may be mediated by adsorption of a layer of lipid at the bacterial surface with interruption or alteration of cell permeability. This might block the adsorption and absorption of essential nutrients, or it might allow outward diffusion of vital cellular components. In general, the inhibitory properties of fatty acids appear more pronounced the longer and more unsaturated is the compound (Nieman, 1954). Also, the effectiveness is related to the configuration of the molecule around any double bonds (Butcher et al., 1976). Stereo-isomerism and three-dimensional configuration are likely to be significant factors determining the amount of adsorption of these molecules.

On the basis of this interpretation the observed antagonistic effects of various substances, such as serum albumin (Dubos, 1947), on the antibacterial activity of lipids can be explained by postulating (1) the formation of complexes with the inhibitory acids, or (2) the competitive adsorption of the antagonist and the fatty acid at the cell wall. The latter explanation presumes that the antagonist is not toxic to the cell. It is possible therefore that the properties of the cell wall of a particular organism determine whether it is susceptible to growth inhibition by free fatty acids and therefore whether it is likely to be a pathogen of the skin.

It seems logical to assume that organisms that are successful in infections of the skin become so partly by virtue of their relative resistance to the fatty acids present there. In our work the inhibitory effect of the fatty acids, especially oleic acid which is the most abundant acid on the skin, was most marked on a strain of Str. pyogenes from a sore throat and less inhibitory on a strain of Str. pyogenes from an outbreak of impetigo. Qualitative results suggested that Staph. epidermidis was more resistant to linoleic acid than Staph. aureus, but this was not confirmed by 
the quantitative tests. Because Staph. epidermidis is considered to be a commensal organism on the skin and Staph. aureus not, a significant difference in susceptibility to fatty acids might have been expected by both methods. However, Staph. aureus is carried by many people for long periods of time and it may be that there are strain differences as were found with the streptococci. Some of the strains used had been subjected to prolonged subculture and this may have affected their behaviour in these tests. Studies are now required with a range of fresh isolates from normal and infected skin.

The techniques have been applied to the antibacterial activity of skin lipids but they are equally applicable to the investigation of the antibacterial activity of lipids in other fields, such as pharmacology, horticulture and industry.

\section{SUMMARY}

New qualitative and quantitative methods are described for the investigation of the antibacterial activity of lipids on solid media by the application of lipid-impregnated filter paper over a lawn of the organisms.

The methods have been used to investigate the antibacterial activity of unsaturated fatty acids that are important in skin defence. Oleic and linoleic acids inhibited Streptococcus pyogenes markedly, Staphylococcus aureus and Staph. epidermidis to a lesser extent and had no effect on Escherichia coli and Pseudomonas aeruginosa. The inhibition of growth of a strain of Str. pyogenes from a sore throat was greater than that of a strain from an outbreak of impetigo. Linoleic acid was a more potent inhibitor of bacterial growth than oleic acid, and with both acids inhibition was more pronounced under aerobic than under anaerobic conditions of incubation.

The methods described could be applied in other fields such as pharmacology, horticulture and industry.

\section{REFERENCES}

Aly, R., Maibach, H. I., Shinefield, H. R. AND Strauss, W. G. 1972. Survival of pathogenic microorganisms on human skin. J. invest. Derm., 58, 205.

Burtenshaw, J. M. L. 1945. Self-disinfection of the skin: a short review and some original observations. Br. med. Bull., 3, 161.

Butcher, G. W., KING, G. AND DYKe, K. G. H. 1976. Sensitivity of Staphylococcus aureus to unsaturated fatty acids. J. gen. Microbiol., 94, 290.

DAvidson, C. 1965. The antibacterial action of free fatty acids and their production from lipids by the normal skin flora. Cambridge University Part II Pathology Research Project, Department of Pathology Library, University of Cambridge.

DuBos, R. J. 1947. The effect of lipids and serum albumin on bacterial growth. J. exp. Med., $85,9$.

FreINKEL, R. K. 1968. The origin of free fatty acids in sebum. I. Role of coagulase negative staphylococci. J. invest. Derm., 50, 186.

Freinkel, R. K. AND SHEN, Y. 1969. The origin of free fatty acids in sebum. II. Assay of the lipases of the cutaneous bacteria and effects of pH. J. invest. Derm., 53, 422.

Galbraith, H., Miller, T. B., Paton, A. M. and Thompson, J. K. 1971. Antibacterial activity of long chain fatty acids and the reversal with calcium, magnesium, ergocalciferol and cholesterol. J. appl. Bact., 34, 803.

Herrmann, F., Prose, P. H. ANd Sulzberger, M. B. 1953. Studies on the ether-soluble substances on the human skin. III. The effect of sweat on the quantity of ether-soluble substances on the skin. J. invest. Derm., 21, 397.

HoLt, R. J. 1971. The esterase and lipase activity of aerobic skin bacteria. Br. J. Derm., 85, 18.

KODICEK, E. AND WORDEN, A. N. 1945. The effect of unsaturated fatty acids on Lactobacillus helveticus and other gram-positive micro-organisms. Biochem. J., 39, 78.

McBride, M. E., Duncan, W. C. AND Knox, J. M. 1975. Physiological and environmental control of gram negative bacteria on skin. Br.J. Derm., 93, 191. 
Marples, R. R., Downing, D. T. and Kligman, A. M. 1971. Control of free fatty acids in human surface lipids by Corynebacterium acnes. J. invest. Derm., 56, 127.

Marples, R. R., Downing, D. T. and Kligman, A. M. 1972. Influence of Pityrosporum species in the generation of free fatty acids in human surface lipids. J. invest. Derm., 58, 155.

Marples, R. R., Kligman, A. M., Lantis, L. R. and Downing, D. T. 1970. The role of the aerobic microflora in the genesis of fatty acids in human surface lipids. J. invest. Derm., 55, 173.

Milyani, R. M. AND Selwyn, S. 1978. Quantitative studies on competitive activities of skin bacteria growing on solid media. J. med. Microbiol., 11, 379.

Naylor, G. R. E. 1970. Bacteria and the skin. In An introduction to the biology of the skin, edited by R. H. Champion, T. Gillman, A. J. Rook and R. T. Sims. Blackwell Scientific Publications: Oxford \& Edinburgh, vol. 1, p. 197.

NAYLOR, G. R. E. AND RoOK, A. J. 1968. Bacterial infections. In Textbook of dermatology, edited by A. Rook, D. S. Wilkinson and S. J. G. Ebling. Blackwell Scientific Publications: Oxford and Edinburgh, vol. 1, p. 594.

NiEman, C. 1954. Influence of trace amounts of fatty acids on the growth of microorganisms. Bact. Rev., 18, 147.

Pollock, M. R. 1948. Unsaturated fatty acids in cotton wool plugs. Nature, Lond., 161, 853.

Puhvel, S. M. AND ReISNER, R. M. 1970. Effect of fatty acids on the growth of Corynebacterium acnes in vitro. J. invest. Derm., 54, 48.

Reisner, R. M. And Puhvel, M. 1969. Lipolytic activity of Staphylococcus albus. J. invest. Derm., 53, 1 .

Reisner, R. M., Silver, D. Z., Puhvel, M. And Sterneerg, T. H. 1968. Lipolytic activity of Corynebacterium acnes. J. invest. Derm., 51, 190.

RicketTs, C. R., SQuire, J. R. AND TOPley, E. 1951. Human skin lipids with particular reference to the self-sterilising power of the skin. Clin. Sci., 10, 89.

Scheimann, L. G., Knox, G., Sher, D. and Rothman, S. 1960. The role of bacteria in the formation of free fatty acids on the human skin surface. J. invest. Derm., 34, 171.

Sharpe, A. N., DyetT, E. J., JACKSON, A. K. AND KILSBY, D. C. 1972. Technique and apparatus for rapid and inexpensive enumeration of bacteria. Appl. Microbiol., 24, 4.

SharPE, A. N. AND JACKSON, A. K. 1972. Stomaching; a new concept in bacteriological sample preparation. Appl. Microbiol., 24, 175.

SOMER VILLE, D. A. 1969. The normal flora of the skin in different age groups. Br.J. Derm., 81, 248.

WALKER, J. E. 1924. The germicidal properties of chemically pure soaps. J. infect. Dis., 35, 557. 